\title{
Contra Clarissa: cultura e desigualdade no primeiro romance de Erico Verissimo
}

\author{
Atilio Bergamini Junior
}

\begin{abstract}
Resumo: Procuro neste ensaio argumentar que a desigualdade é um dos "agentes estruturais" (conforme formulação de Antonio Candido) de Clarissa, romance publicado em 1933 por Erico Verissimo. Para compor as reconhecidas atitudes de boa menina - curiosa, solidária e preocupada com as injustiças sociais - o romance apresenta sua personagem principal também com um forte racismo e um preconceito latente a respeito de si própria. Nesse sentido, a estrutura do romance focaliza tensionamentos, mas atenua as contradições das cenas, o que ajuda a constituir, por fim, o efeito lírico pela qual Clarissa se notabilizou.
\end{abstract}

\begin{abstract}
: the aim of this essay is to demonstrate that inequality is one of the 'structural agents' (according to Antonio Candido's formulation) of Clarissa, Erico Verissimo's novel published in 1933. To compose the recognized attitudes of what would be a good girl - curious, solidary and worried about social injustices -, the novel also had to show the character with a strong racism and a latent prejudice about herself. Thus, the novel structure attenuates tensions that are in the first plan of its propositions, but it attenuates the effect of some scenes, giving, finally, the lyric effect that made the novel noticeable.
\end{abstract}

Palavras-chave: Erico Verissimo, Porto Alegre, anos 1930, desigualdade.
Keywords: Erico Verissimo, Porto Alegre, 1930’s, inequality.

\section{A desigualdade como forma da cultura}

Clarissa, primeiro romance de Erico Verissimo, conta a história de uma garota do interior que vai para a capital estudar na Escola Normal. Ela tem 13 para 14 anos e se hospeda na pensão de uma tia - um microcosmo da sociedade porto-alegrense da época. Publicado em 1933, o romance pode ser lido em conjunto com outros quatro livros de Verissimo.

Sabe-se que o autor escreveu esses livros numa Porto Alegre com aproximadamente $64 \%$ de analfabetos (TORRESINI, 1999, p.42). Nessa cidade, levas de imigração e migração e a incrementação dos movimentos comerciais e industriais transformaram o panorama urbano - diversificando o setor terciário e oferecendo ao escritor uma gama de conflitos e tensões vazados pelo capitalismo. Com estrutura comercial, além de saída portuária e terrestre, a capital fazia as vezes de porto de escoamento da agricultura, tornada mais

\footnotetext{
${ }^{*}$ Mestrando
} 
complexa com a inserção econômica - num mercado nacional e mundial (pelo consórcio das guerras mundiais) - dos povoamentos de imigrantes. A cidade logo se tornou a maior concentração industrial do Rio Grande do Sul (TORRESINI, 1999).

A configuração de Porto Alegre, apenas esboçada acima, possibilitou, em Clarissa, a representação de personagens como o Amaro, funcionário de banco; Barata, revendedor de contrabandos; Belmira, doméstica; Zina, dona de pensão; Couto, desempregado; Clarissa, estudante; o amolador, os gringos, estudantes de cursos preparatórios, universitários e assim por diante. Além desses, toda uma cepa de apaixonados por música (clássica e popular), cinema e literatura.

Veja-se: as caracterizações se estabelecem pelas profissões de cada um. São índices importantes, porque, ao longo do livro - e da obra de Verissimo -, as insígnias profissionais prevalecem diante das insígnias que Raymundo Faoro (2003) talvez denominasse como estamentais: a dos majores, coronéis e estancieiros, na maior parte das vezes, representados em tons decadentes, deslocados e, não raro, caricatos.

$\mathrm{Na}$ cidade (e no romance), as relações do mundo rural - o compadrio, a violência ligada à manutenção das propriedades (políticas inclusive) - são esgarçadas por relações abstraídas pelo valor de troca, pelo dinheiro.

Um artigo de Charles Monteiro (2005) aponta uma série de dados que embasa a interpretação acima. Conforme o autor, Otávio Rocha (1924-1928), chamado de "remodelador da cidade" pelos jornais da época, abriu avenidas largas, pavimentadas, iluminadas, arborizadas e com calçadas. Para isso, contraiu empréstimos no exterior, aumentou impostos e tomou a cargo da Intendência municipal os serviços de distribuição de água e limpeza urbana. Abriu e reformulou o centro - onde morava e circulava a população empobrecida - para "a circulação de automóveis, das elites em novos vestuários e para a construção de novos prédios".

Esse processo foi acompanhado de uma campanha de "saneamento moral" do centro da cidade com o combate à prostituição, à mendicância, ao jogo, ao alcoolismo, bem como às habitações populares (cortiços, porões e pensões populares). (...)

Nos anos 1930, aprofundou-se o processo de expansão da malha urbana na administração de Alberto Bins (1928-1937). (...) Os automóveis e os ônibus concorreram gradualmente para alterar a forma de pensar a organização e os deslocamentos no espaço urbano. (MONTEIRO, 2005)

Em meio à complexidade do capitalismo industrial, houve condições para o comércio e a produção de livros. Isso, entretanto, não leva a concluir - sem maiores mediações - que se trata de um movimento unicamente positivo, como se livros tornassem a sociedade melhor, independentemente de qualquer condição. Os livros eram e continuam sendo, também, 
mercadorias produzidas no horizonte de um jogo de distinção. Isto é, sua apropriação ajuda a estabelecer desigualdades que podem se transformar, por meio de hegemonias monopolistas e até certo ponto violentas na representação simbólica do social, em sinais de status. Em outros termos, a produção e a distribuição de livros passam pela reprodução das desigualdades da vida porto-alegrense - que, como fica claro acima, se urbanizou a partir do ponto-de-vista das elites.

Tudo faz lembrar as teses sobre o conceito de história, de Walter Benjamin (1996), principalmente a célebre tese número 7. Os dominadores de todos os tempos, afirma Benjamin, participam de um cortejo triunfal, no qual mostram os despojos de sua conquista. Tais despojos são os "bens culturais”. Refletindo sobre o papel do materialista histórico diante dos bens culturais, Benjamin invoca o horror, porque:

[os bens culturais] Devem sua existência não somente ao esforço dos grandes gênios que os criaram, como à corvéia anônima dos seus contemporâneos. Nunca houve um monumento da cultura que não fosse também um monumento da barbárie. E, assim como a cultura não é isenta da barbárie, não o é, tampouco, o processo de transmissão da cultura. (BENJAMIN, 1994 [1940], p.225, grifos meus)

Numa cidade com $64 \%$ de analfabetos e outros inúmeros analfabetos funcionais, organizada para a circulação e o bem-estar de uma ínfima parte da população, quantas pessoas podiam ler e liam? E que razão temos para vislumbrar - como não raro acontece - no crescimento da Livraria e Editora Globo algo como um símbolo do desenvolvimento da Porto Alegre como um todo?

Se a Globo - com o incremento de uma política nacionalista de educação e cultura de fato contribuiu para a formatação do mercado cultural gaúcho, abriu um espaço de possibilidades e inovações para escritores, tradutores e críticos, além de ampliar o público leitor, não se configuram razões suficientes para deixar de ver as condições de extrema desigualdade em que isso ocorreu ou, posto em termos talvez mais corretos, as condições de extrema desigualdade que possibilitaram o boom da indústria cultural na Porto Alegre dos anos 1930.

Nessas condições de desigualdade, a circulação dos objetos culturais se realiza de um modo específico. Estabeleceu-se em Porto Alegre, conforme o que se depreende do artigo de Charles Monteiro, uma elite que procurou se sobrepor violentamente aos estratos empobrecidos da população, inclusive com projetos de "higienização" moral. Por isso, entender os objetos culturais como índices de progresso universal pode ser apressado, sobretudo numa sociedade em que a "cultura" serve para distinguir uma vez mais (em reforço), a partir de seu consumo e produção, os pobres dos ricos, as mulheres dos homens e 
assim por diante, com chave positiva no segundo pólo da distinção.

A partir daí, é preciso averiguar de que maneira a desigualdade é um dos motes da organização interna de Clarissa, não em termos de mera correspondência entre organização social e conteúdo - o que seria grosseiro -, mas em termos de estruturação do enredo e da construção lingüística do entrecho.

Tomarei uma passagem - ver a seguir - como metonímia da estrutura do romance. Acredito que ela evidencia, no seu abafado jogo de tensão, um enredo que circunscreve duas personagens em classes distintas, através de procedimentos quase imperceptíveis. Dudu, amiga da personagem principal, é uma menina rica. Lê romances, assiste a filmes, toma sorvete, anda de carro com diversos namorados. Passeia por toda a cidade. Clarissa, mais pobre, circula pela cidade tanto quanto seu dinheiro: quase nada. Ela só pode andar a pé - não tem sequer o suficiente para o bonde. Vai à missa, mais por socialização do que por religiosidade, lê romances (proibidos pela tia, com títulos como A que morreu de amor...). É sistematicamente repreendida para que não olhe para os meninos e não vá ao cinema. Se apropriando de romances, ela faz, em diversas passagens, comparações entre a literatura e a vida, evidenciando a literatura como um dos motores de construção de representações de si própria.

Essas duas garotas, Clarissa e Dudu, se encontram num momento em que Clarissa lê (e no único momento em que alguém de fora entra na pensão onde se passa o romance):

\footnotetext{
Dudu olha o título. Faz um gesto depreciativo:

- A que morreu de amor. Conheço essa droga. A tia Beta tem. Pura besteira...

Clarissa faz uma careta de censura:

- Olha Dudu, um livro tão bonito, nem deves dizer isso...

$[\ldots]$

[Dudu] Tem a voz grossa meio rouca, e uma maneira de falar toda especial: "Te digo, benzinho!" "É da pontinha!" "É do outro planeta!" Dudu! Dudu que tem liberdade, sapatos de salto alto, vestidos bonitos, namorados... Dudu que vai ao cinema e aos bailes quando quer... Dudu!
}

A passagem representa uma garota rica que se dirige criticamente à literatura. Mesmo que não tenha lido os livros de que fala, a classe na qual ela sustenta sua auto-estima reconhecida e reforçada pela submissão de Clarissa -, lhe dá segurança para falar, criticar, desdizer. Clarissa, com circulação circunscrita, em termos físicos, à pensão de sua tia, e, em termos culturais, aos livros que lê escondida, se inscreve na sua timidez que é uma timidez não de quem não sabe do que está falando (ela leu o romance, ao contrário de Dudu), mas de quem gosta (e deve gostar) de algo tido, pela classe mais alta, como ridículo e estúpido. A cultura, portanto, é um meio de distinção. Em última instância, Dudu não discute o livro; mais do que isso, ela explicita quem é que está falando e para quem: uma garota rica para uma 
garota pobre.

No final do trecho citado, Clarissa faz uma enumeração em que a liberdade aparece ao lado de sapatos de salto alto e vestidos bonitos, condicionando, em seguida, a liberdade à classe de Dudu. A ingenuidade da personagem quase faz a enumeração disparatada (liberdade ao lado de sapatos, vestidos e namorados) passar desapercebida. Para levar adiante a argumentação, lembro os efeitos de ironia que um Machado de Assis tirava desse tipo de enumeração. Nesse caso, não há ironia, ou seja, Clarissa compra os valores simbólicos que ela não pode pagar - embora, ao que parece, o escritor tenha procedido assim para explicitar ao leitor justamente a ingenuidade de Clarissa. A cena, uma contradição patente, é de fraca tensão porque não aprofunda a incomunicabilidade do diálogo que, nessa incomunicabilidade, transfunde um forte "sentido social simbólico" (CANDIDO, 2000, p.7). Dudu, a menina rica, é como que proprietária da cidade inteira, uma cidade destruída e reconstruída ao gosto de sua classe.

\section{A cultura como forma da desigualdade}

Como a desigualdade é rosto e máscara do livro (enquanto enredo e enquanto produto cultural dos anos 1930), penso ser necessário discutir a proposição de Torresini (1999, p.108) quando analisa, em meio a uma notável organização de dados, as relações entre a industrialização do Brasil e a indústria cultural em Porto Alegre:

Tal processo [o da industrialização do Brasil e da produção de uma indústria cultural] vem acompanhado, na década de 1930, da ascensão de Getúlio Vargas, que ao inaugurar um estilo de política dependente da participação das massas, estimula a radiodifusão e o desenvolvimento do cinema nacional, do disco, da imprensa e do livro.

Tomado isoladamente, talvez o parágrafo ecoe um tom de subserviência que não é, quero deixar bem saliente, o tom que se constrói depois da leitura do livro como um todo. Ainda assim, a cultura foi um instrumento político de Getúlio Vargas e durante anos a produção cultural nos mais diversos suportes pagou o preço de suas relações com o Estado. Que nem sempre as tentativas da política getulista tenham rendido bons frutos (culturais e políticos), isso é outra história. Mas entender as políticas culturais, e as culturas políticas, de Getúlio, antes e depois do Estado Novo, como políticas "dependentes" das massas e como "estímulo" à cultura faz coincidir perigosamente o discurso teórico e o discurso político. Fica posta a questão: não estaremos, nas disciplinas que investigam a literatura, notando com 
exagerado jubilo um processo que mereceria ser visto com mais resistência crítica e negatividade?

Francisco de Oliveira (1987) aponta como a industrialização - dos anos 1930 até os anos de ditadura militar - urbanizou a paisagem brasileira, criou um imenso exército industrial de reserva e promoveu como que o consumo, pelos trabalhadores, da sua própria reprodução como mão-de-obra. O economista procura demonstrar que a industrialização aumentou os índices de exploração do trabalho. Com isso, houve aumento da acumulação de renda, e - segundo entendo - uma capitalização de certos sinais de desigualdade social, entre eles, os objetos culturais. O termo sociológico da dialética que procuramos compreender (situações sociais da cidade e romance) é interno ao termo literário, fazendo rasurar a dualidade e revelando fragmentos de uma totalidade estrutural que está na raiz do efeito lírico em Clarissa.

O romance - nessa dialética - não é apenas seu enredo. Como Clarissa faz parte do "boom" literário nos anos trinta, ele pode ser entendido, deixando de lado, por um momento, a necessária (nesse caso) primazia do estético, pelas suas condições de aparecimento. Não há razão para supor que a industrialização da cultura tenha operado com índices de exploração diferentes dos da industrialização em si. A indústria do livro, portanto, não se insere num ambiente de mero desenvolvimento - embora alguns pontos isolados possam dar essa impressão -; pelo contrário, a indústria do livro, em Porto Alegre e no Brasil, surge num ambiente de incrementação do subdesenvolvimento.

Dos apontamentos acima, aprendemos que Porto Alegre, com um comércio e uma indústria crescentes (e um setor terciário em expansão), constitui-se um espaço de desigualdades. Quase ao mesmo tempo, esse espaço de desigualdades, se tornou um "agente da estrutura" dos primeiros livros de Erico Verissimo ou ao menos de Clarissa. De uma ou de outra forma, os primeiros romances do autor examinam a desigualdade entre as classes. Ora eles criam uma topologia (cidade alta e cidade baixa), ora fazem os pobres nascerem e morrerem em hospitais insalubres e os ricos freqüentarem hospitais bem equipados. Contudo, como vimos, é pouco - e até mesmo grosseiro - fazer correlações simples entre conteúdos sociais e conteúdos literários. Em Clarissa, aparecem uma sucessão de tons, posturas e relações do narrador e do foco narrativo que fazem ver em nível lingüístico aquela desigualdade que reparamos, em nível do enredo, na passagem em que conversam Dudu e Clarissa.

Ao longo dos seus quatro primeiros romances, Erico Verissimo marca ostensivamente a fala de pobres e negros. Eles estão distinguidos em termos lingüísticos. "Ué, cangica, D. 
Crarissia!...” (p.109) "Eles não querem que os guris vão na casa dos otro." (p.110) e assim por diante, com personagens como Xexé (de Um lugar ao sol), Belmira (de Clarissa) e outros, todos pobres e negros ou mulatos.

Esse dado empírico, reposto para o todo estrutural do romance, evidencia um tratamento preconceituoso. Preconceituoso porque, nas vezes em que personagens de classe média ou média-baixa aparecem com marcas de fala (trocando o "r" pelo "l" ou fazendo "f" onde haveria "ss"), essas marcas reforçam um caráter, por assim dizer, rebaixado até risível. Como nas personagens de classe-baixa, os índices lingüísticos não procuram reforçar descrições de rebaixamento, eles - os índices lingüísticos - resultam, ao leitor mais ingênuo, numa depreciação, pelo senso comum, da personagem representada.

Se poderia argumentar, nesse caso, que tudo vai na conta do foco narrativo, que, afinal, está na personagem Clarissa? Sim e não.

Sim, porque Clarissa é uma personagem extremamente racista. Em dado momento da história, por exemplo, ela repara quantas crianças estão brincando no pátio. "São quatro. Com Luzia seriam cinco. Mas negro não entra na conta." (p.109) Em outra passagem, faz da mulatice de Belmira razão de sua superioridade, quando Amaro cumprimenta as duas da mesma maneira. "Nem ao menos um cumprimento especial para ela [Clarissa]. Igualada com a mulata Belmira. Desaforo." (p.6)

E não, não se poderia debitar a interpretação apenas no racismo da personagem porque, em seguida, numa inserção do narrador - que se repetirá num momento em que o foco narrativo acompanha Amaro - leremos o seguinte: "Luzia fica séria, os olhos chispam, a beiçarra cai." (p.109)

Parágrafos acima, passamos brevemente por uma descrição de Dudu - a menina rica e loira. Em nenhum momento do livro, a garota foi descrita com uma palavra como "beiçarra". Nesse caso específico, o narrador e Clarissa tem percepções coincidentes.

Na fatura verbal de Clarissa, bem como na constituição do enredo e da estrutura, aparecem uma série de índices que nos obrigam a insistir na idéia de que o mercado cultural na Porto Alegre dos anos 1930 foi produzido e se produziu numa sociedade desigual - e a desigualdade é evidenciada, por exemplo, no que interpretei aqui como racismo na personagem e no narrador. Extrapolar daí e debitar na conta do escritor um racismo que é social, seria reduzir a questão a um âmbito inconsistente e especulativo. Mas deixar de notar que narrador e personagem são racistas seria reconhecer como legítima uma interpretação autorizada por certa cegueira. A ingenuidade da menina Clarissa, Erico Verissimo soube contruí-la muito bem, é repleta de frinchas - e, por vezes, chocante. Por que tal choque não 
tem sido reparado pelas leituras feitas? Por que a ênfase, em diversas interpretações, nos aspectos líricos do livro? Nesse caso, a teoria do sociólogo francês, Pierre Bourdieu, traz uma contribuição importante. Escreve ele:

\begin{abstract}
A forma pela qual as produções simbólicas participam mais diretamente das condições sociais de sua produção é também aquilo com que exercem seu efeito social mais específico, a violência propriamente simbólica, que somente pode ser exercida por aquele que a exerce e suportada por aquele que a suporta sob uma forma tal que ela permaneça como que desconhecida, isto é, reconhecida como legítima (BOURDIEU, 1996, p.134).
\end{abstract}

Talvez seja o caso de ressaltar como temos desconhecido importantes nuances de Clarissa - livro e personagem. A leitura que entende o enredo a partir de seus dotes líricos silencia a respeito de seus pressupostos de leitura. A presente crítica, ao se produzir, não pode deixar de fazer parte de uma luta por legitimação - ainda que pretenda, em definitivo, construir-se longe dos efeitos de hegemonia -, baseada, agora, não no elogio repercutivo do objeto cultural, mas na investigação e na demonstração de particularidades desse objeto e nas consequiências que essa investigação tem para o fazer de si como crítica. A boa menina (tão boa por ser racista e preconceituosa?) se constitui, nessa leitura, como uma expressão que mascara "experiências primitivas do mundo social e os fantasmas sociais [...] A expressão só pode enunciá-los sob uma forma que os torna irreconhecíveis porque ela [a expressão] não pode admitir enunciá-los" (BOURDIEU, 1996, p.137).

Na forma de Clarissa, a partir de uma derivação dos estudos de Theodor W. Adorno, seria possível notar o desnível material e simbólico que, a partir da sociedade, faz a obra ter efeitos - e, a partir da obra, produz saber a respeito da sociedade. Caso se pudesse, por procedimentos teóricos, reconstruir a forma do livro no enredo social - construído pela Economia, Sociologia e História -, se veria que a forma (a estruturação dos capítulos, a tensão - ou falta de - entre personagens, o nível lingüístico) abstrai o enredo social (sem que isso deva ser lido, necessariamente, com sinal estético negativo).

$\mathrm{Na}$ boa dialética, a forma interpretada no veio social torna concretas desigualdades que estão abstratas no conteúdo do livro - embora o estruturem, ao oporem personagens. Isso porque o livro só pode fazer sentido - como universalidade repetível - ao preço de tornar esquecidas as desigualdades concretas que se notam na industrialização do Brasil. Em termos mais palpáveis, a forma se torna ingênua como uma mercadoria fetichizada, na medida em que representa, para alguns leitores, apenas o pensamento de uma adolescente boazinha, na Porto Alegre dos anos 1930, uma cidade também ela ingênua, repleta de filmes norteamericanos e histórias romanescas. Por tudo isso, me parece, é preciso ver em Clarissa o que o livro nos mostra que ela é. E ela é uma personagem das mais contraditórias, racista, 
boazinha, contida, recatada, acomodada, curiosa, católica, terna, solidária, triste, feliz, sonhadora. Uma personagem construída num livro ambíguo, atravessado por pulsões e tensões entre grupos abstraídas em algumas leituras, mas nem por isso - quando mediadas pela totalidade estrutural - menos concretas.

Se a desigualdade é mesmo "agente estrutural" do livro, por que o livro é lido e tem sido lido como um pequeno passeio lírico, descompromissado, pela infância de uma menina que vai se tornar professora e casar com a personagem Vasco num livro de 1940, o Saga? Os argumentos que construí aqui, parecem levar esse questionamento a ver-se frente às tensões constantes no interior do romance; tensões abafadas pela ingenuidade da personagem construída com mão de mestre pelo escritor. A ingenuidade traz para primeiro plano a visão de Clarissa e dá a ela um efeito de verdade que esconde todo um arcabouço de racismo e preconceito. Para que Clarissa seja tão boazinha, enfim, é preciso que ela seja racista e preconceituosa, mas é preciso, sobretudo, que esse racismo e esse preconceito (que é antes de mais nada um auto-preconceito) estejam soterrados pela ingenuidade. Assim resolvida no plano individual, a questão perde o caráter conflitivo e abrangente que possui e escapole pelo lirismo.

Portanto, caso a interpretação que propus se sustente, a forma literária de Clarissa propõe aos leitores - de modo não totalmente satisfatório - a contradição de uma Porto Alegre que produziu uma indústria do livro no exato momento em que recriou e reforçou divisões e segregações entre as classes ou grupos sociais, fazendo o subdesenvolvimento ser razão direta do desenvolvimento, a barbárie e o preconceito aparecerem - em certos casos no mesmo significante em que aparecem a cultura e o bom senso. Posto que isso tudo tensiona a recepção que fazemos do romance nos dias atuais, as condições de leitura ainda reprimem uma questão que - não obstante - salta aos olhos: a da desigualdade refundada no preconceito e no racismo, ditados num ritmo lírico e tenro, como se nada estivesse acontecendo.

\section{Referências}

BOURDIEU, Pierre. A economia das trocas lingüísticas: o que falar quer dizer. São Paulo: Edusp, 1996.

CANDIDO, Antonio. Literatura e sociedade. São Paulo: T. A. Queiroz-Publifolha, 2000.

CORADINI, Odaci Luiz. As missões da "cultura" e da "política": confrontos e reconversões 
de elites culturais e políticas no Rio Grande do Sul (1920-1960). In: Estudos Históricos, Rio de Janeiro, n. 32, p. 125-144, 2003.

FAORO, Raymundo. Os donos do poder: formação do patronato político brasileiro. São Paulo: Globo, 2001.

OLIVEIRA, Francisco de. A economia brasileira: crítica à razão dualista. Petrópolis: Vozes, 1987.

MONTEIRO, Charles. A porto alegre de Erico Verissimo. In: Revista Ciências e Letras, Porto Alegre, n.38, p.24-35, jul./dez. 2005. Acessado dia 22/11/2007 em: http://www.fapa.com.br/cienciaseletras/publicacao.htm

TORRESINI, Elisabeth Rochadel. Editora Globo: uma aventura editorial nos anos 30 e 40 . São Paulo-Porto Alegre: Edusp, Com-Arte, Ufrgs, 1999.

VERISSIMO, Erico. Caminhos cruzados. Porto Alegre-Rio de Janeiro: Editora Globo, 1984.

VERISSIMO, Erico. Clarissa. Porto Alegre-Rio de Janeiro: Editora Globo, 1984.

VERISSIMO, Erico. Música ao longe. Porto Alegre-Rio de Janeiro: Editora Globo, 1984.

VERISSIMO, Erico. Saga. Porto Alegre-Rio de Janeiro: Editora Globo, 1984.

VERISSIMO, Erico. Um lugar ao sol. Porto Alegre-Rio de Janeiro: Editora Globo, 1984. 